\title{
Espécies novas de Epanthidium Moure e de Austrostelis Michener \& Griswold (Hymenoptera, Apidae, Megachilinae) ${ }^{1}$
}

\author{
Danúncia Urban ${ }^{2}$
}

${ }^{1}$ Contribuição n ${ }^{0} 1601$ do Departamento de Zoologia, Universidade Federal do Paraná.

${ }^{2}$ Departamento de Zoologia, Universidade Federal do Paraná. Caixa Postal 19020, 81531-980 Curitiba-PR, Brasil. Bolsista do CNPq. urban@ufpr.br

\begin{abstract}
New species of Epanthidium Moure and of Austrostelis Michener \& Griswold (Hymenoptera, Apidae, Megachilinae). Epanthidium araranguense sp. nov. from Santa Catarina, Epanthidium chapadense sp. nov. from Mato Grosso do Sul, Epanthidium flavoclypeatum sp. nov. from Minas Gerais, Austrostelis amapaensis sp. nov. from Amapá, Austrostelis santaterezae sp. nov. from Espírito Santo and Austrostelis silveirai sp. nov. from Minas Gerais are described and illustrated. A key to identify the species of Austrostelis is presented.
\end{abstract}

KEYWORDS. Anthidiini; new species; neotropical; taxonomy.

RESUMO. Espécies novas de Epanthidium Moure e de Austrostelis Michener \& Griswold (Hymenoptera, Apidae, Megachilinae). São descritas e ilustradas: Epanthidium araranguense sp. nov. de Santa Catarina, Epanthidium chapadense sp. nov. de Mato Grosso do Sul, Epanthidium flavoclypeatum sp. nov. de Minas Gerais, Austrostelis amapaensis sp. nov. do Amapá, Austrostelis santaterezae sp. nov. do Espírito Santo e Austrostelis silveirai sp. nov. de Minas Gerais. Uma chave para a identificação das espécies de Austrostelis é apresentada.

PALAVRAS-CHAVE. Anthidiini; espécies novas; neotropical; taxonomia.

Foram revisadas por Urban (1995) 18 espécies sulamericanas de Epanthidium Moure, 1947; mais três espécies novas são propostas neste trabalho. Quanto a Austrostelis Michener \& Griswold, 1994, três espécies foram reestudadas por Urban (1999), uma foi descrita do nordeste brasileiro, $A$. maranhensis Urban, 2005, e neste trabalho são dadas a conhecer mais 3 espécies novas. As medidas que constam nas descrições são dadas em milímetros, o material-tipo das espécies descritas está depositado na Coleção de Entomologia Pe. J. S. Moure, Departamento de Zoologia, Curitiba (DZUP) e nas Coleções Taxonômicas da UFMG, Belo Horizonte (DZMG).

\section{Epanthidium araranguense sp. nov.}

(Figs. 1 e 4)

Diagnose. Fêmea com a cabeça preta, menos as estrias amarelas das paroculares superiores, a faixa pós-ocelar ferrugínea e duas nódoas amarelas no meio da fronte, uma supraclipeal e a outra junto ao ocelo mediano; primeiro tergo com faixas laterais amarelas manchadas de ferrugíneo, o segundo preto e os três tergos seguintes com nódoas laterais amarelas.

Holótipo fêmea. Comprimento aproximado 10,45; comprimento da asa anterior a partir do ápice do esclerito costal 8,38; largura da cabeça 3,58. Tegumento preto na cabeça, inclusive nas mandíbulas, exceto duas nódoas no meio da fronte e estrias paroculares dorsais curtas e estreitas, amarelas, as nódoas frontais amplamente separadas, uma supraclipeal muito pequena e a outra pouco maior e arredondada perto do ocelo mediano; faixa pós-ocelar ferrugínea, prolongada atrás dos olhos na parte dorsal das genas; antenas ferrugíneas do escapo ao terceiro flagelômero, com áreas castanhas no pedicelo e nos flagelômeros, no restante enegrecidas. Mesossoma preto com máculas laterais ferrugíneas em "L" invertido no mesoscuto, as axilas e a metade distal do escutelo ferrugíneas. Tégulas ferrugíneo-acastanhadas, asas tingidas de enegrecido; pernas pretas menos as tíbias ferrugíneas, os tarsos castanhos e os basitarsos posteriores com a metade basal ferrugínea. Tergos pretos, o primeiro com faixas amarelas laterais orladas irregularmente com ferrugíneo, segundo tergo preto, os três seguintes com um par de nódoas amarelas dorsais, as nódoas maiores e ovaladas no terceiro e muito reduzidas no quarto tergo; os dois distais pretos.

Pilosidade branca nas paroculares inferiores e genas, castanha no vértice e creme nas demais áreas cefálicas; creme e ereta no dorso do mesossoma; branca, longa e decumbente nos mesepisternos; pouco conspícua e extremamente curta nos tergos; escopa ventral branca.

Clípeo um pouco abaulado, denso-pontuado e sem carena; tégulas densamente pontuadas; axilas arredondadas; discrímen mesepisternal com projeção em arco na metade anterior; quarto e quinto tergos com carenas laterais terminando em dentes muito pequenos; o sexto tergo densopontuado, com projeções laterais dentiformes e tubérculo subapical carenado ao longo do meio, sem carena basal; sexto esterno com projeções laminadas altas, paralelas ao bordo lateral, projetadas para trás em forma de dentes agudos, com recorte côncavo entre os dentes e a projeção mediana, esta com a ponta mais estreita que a metade da largura do recorte. 
Holótipo fêmea. "Brasil, Santa Catarina / 9 km a E de Araranguá / $28^{\circ} 57 \mathrm{~S} 49^{\circ} 25 \mathrm{~N} /$ 17.XI.2002. G. Melo / área de dunas” (DZUP).

Comentário. Na chave de Urban (1995) esta espécie é tratada como Epanthidium confusum (Smith, 1879), conhecida de Mendoza e Córdoba, Argentina, a qual se assemelha a esta espécie tanto no colorido como nas estruturas tegumentares. Entretanto, E. confusum difere de E. araranguense sp. nov., pelos dois tergos basais ferrugíneos com faixa marginal enegrecida; escutelo inteiramente ferrugíneo; o sexto esterno com a projeção mediana curta, truncada e tão larga como os recortes laterais.

\section{Epanthidium chapadense $\mathbf{s p . ~ n o v . ~}$}

(Figs. 2 e 5)

Diagnose. Macho com faixa pós-ocelar, axilas, quase todo o escutelo e as pernas ferrugíneos; mesoscuto com máculas laterais amarelo-ferrugíneas em " $\mathrm{L}$ " invertido e, faixa amarela larga orlada com ferrugíneo nos três tergos basais.

Holótipo macho. Comprimento aproximado 9,67; comprimento da asa anterior a partir do ápice do esclerito costal 7,49; largura da cabeça 3,51. Tegumento preto predominando na cabeça, exceto as mandíbulas amarelas com as margens e a parte apical pretas; o clípeo e as paroculares inferiores amarelos, as máculas paroculares estreitando muito dorsalmente e terminando um pouco acima do ocelo mediano; duas nódoas amarelas no meio da fronte, uma triangular na área supraclipeal e outra elipsóide próxima ao ocelo mediano; faixa ferrugínea no vértice, atrás dos ocelos, mais estreita no meio e prolongada na parte dorsal das genas. Antenas com os artículos basais ferrugíneos e enegrecida do terceiro flagelômero ao distal. Mesossoma preto, menos as duas estrias látero-basais amarelo-ferrugíneas em forma de "L" invertido no mesoscuto, com o ramo basal mais largo e com um prolongamento muito fino para o meio e, o lateral estreitíssimo e não chegando ao ápice do esclerito; axilas e quase todo o escutelo ferrugíneos, o escutelo preto só no terço basal. Tégulas castanho-amareladas, asas tingidas de castanho; pernas com os artículos basais castanho-enegrecidos até a metade dos fềmures, com uma tonalidade mais escura nas coxas e mais pálida nos fêmures, parte restante dos fêmures, tíbias e tarsos amarelo-ferrugíneos, a face dorsal das tíbias anteriores e medianas e a dos basitarsos posteriores mais amarelada. Os três tergos basais castanhos com faixa amarela larga orlada irregularmente com ferrugíneo-acastanhado e a margem castanha estreita, um pouco mais larga e angulosa no meio, resultado do estreitamento da faixa amarela. Quarto ao sexto tergo pretos com mácula dorsal amarelo-escura e a margem castanha, muito estreita no sexto; sétimo tergo castanho. Flancos ventrais dos três primeiros tergos e os esternos ferrugíneo-amarelados.

Pilosidade creme na cabeça e dorso do mesossoma, muito curta no mesoscuto, branca e alongada nos mesepisternos, também branca porém muito curta nos tergos; creme e densa na faixa marginal do segundo e no terceiro esterno.

Clípeo um pouco abaulado, com pontuação densa, sem áreas lisas e sem carena; tégulas com área discal polida; axilas arredondadas; sétimo tergo com o espinho mediano um pouco mais longo que os lobos laterais, estes largos e separados do espinho mediano por recorte em arco tão largo como os lobos; discrímen mesepisternal com uma projeção em arco rebaixado, na metade basal; segundo esterno com projeções laterais digitiformes.

Holótipo macho. "Oct." [outubro]; "Chapada" (DZUP). Foi coletado na Chapada dos Guimarães, Mato Grosso.

Comentário. Na chave proposta por Urban (1995) esta espécie entrou como E. aureocinctum Urban, 1995, pelas faixas amarelas dos três tergos basais, porém difere por possuir máculas ferrugíneas elipsóides no vértice, o dorso do mesossoma inteiramente preto e as pernas em parte amarelas e em parte pretas.

\section{Epanthidium flavoclypeatum sp. nov.} (Figs. 3 e 6 )

Diagnose. Macho com o clípeo e nódoa supraclipeal amarelos; mandíbulas e áreas paroculares pretas; segundo e terceiro tergos com faixa discal amarela larga, orlada com ferrugíneo; o tergo basal com faixa em parte amarela e em parte ferrugínea, estreita no dorso e larga nos flancos.

Holótipo macho. Comprimento aproximado 10,32; comprimento da asa anterior a partir do ápice do esclerito costal 8,97; largura da cabeça 3,51. Tegumento preto na cabeça, inclusive nas mandíbulas e paroculares, menos o clípeo amarelo com os cantos basais pretos, pequena área supraclipeal amarela e estria curta ferrugíneo-acastanhada atrás dos ocelos, junto ao occipício. Mesossoma preto, inclusive as tégulas; asas tingidas de enegrecido; pernas em grande parte pretas, porém de cor âmbar-acastanhada na face anterior das tíbias anteriores e medianas, face posterior das tíbias posteriores e a ponta de todos os fêmures; tarsômeros com mescla de enegrecido e âmbar-acastanhado. Tergos pretos, o primeiro com faixa amarela muito estreita dorsalmente e larga nos flancos, a faixa amarela com manchas ferrugíneas entre a face dorsal e as laterais; segundo e terceiro tergos com faixa discal amarela larga; tergo distal com o ápice castanho-avermelhado. Dois esternos basais pretos, os demais castanhos.

Pilosidade branca em quase toda a cabeça, castanha no vértice; branca nos mesepisternos e nos tergos; creme e muito curta no mesoscuto; branca, curtíssima e esparsa nos tergos, um pouco alongada nos flancos; esbranquiçada na depressão apical do segundo esterno, creme-acastanhada e densa na área discal do terceiro esterno.

Clípeo com pontuação densa, sem áreas lisas e sem carena; tégulas com pequena área discal polida; axilas arredondadas; sétimo tergo com o espinho mediano um pouco mais longo que os lobos laterais, estes largos e separados do espinho 

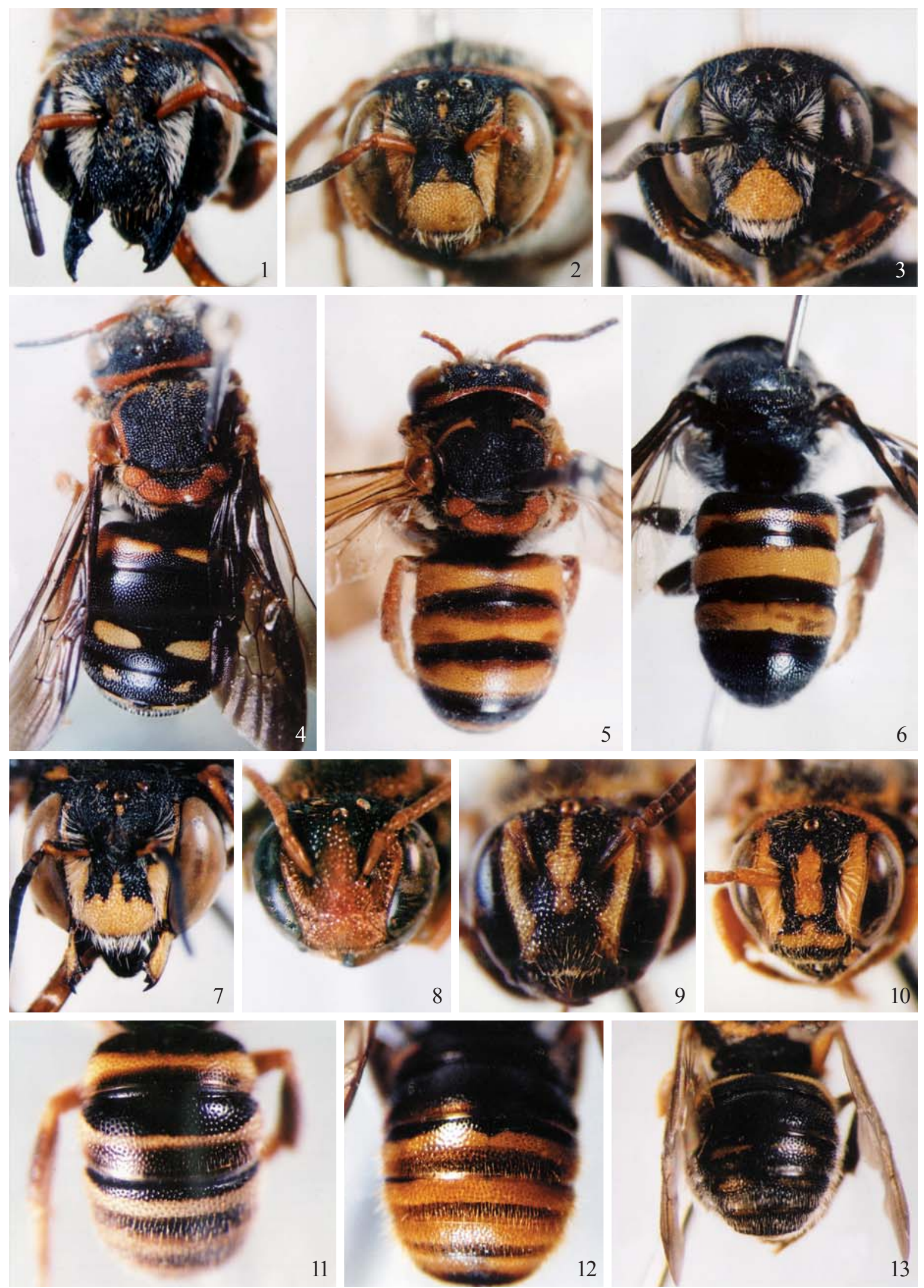

Figs. 1-13. Holótipos. Vista frontal da cabeça: 1, Epanthidium araranguense sp. nov., 2, E. chapadense sp. nov., 3, E. flavoclypeatum sp. nov., 7, E. aureocinctum Urban, 1995; 8, Austrostelis amapaensis sp. nov., 9, A. santaterezae sp. nov., e 10, A. silveirai sp. nov. Vista dorsal do mesossoma e tergos: 4, E. araranguense, 5, E. chapadense, 6, E. flavoclypeatum. Tergos de: 11, Austrostelis amapaensis, 12, A. santaterezae, e 13, A. silveirai. 
mediano por recorte em arco tão largo como os lobos; discrímen mesepisternal com projeção em arco rebaixado, na metade basal; segundo esterno com projeções digitiformes laterais.

Holótipo macho. "Brasil, Minas Gerais, / Corinto, 16-31.X.1979 / C. Elias leg." (DZUP). Três parátipos machos com a mesma procedência (DZUP).

Comentários. No tergo basal dos parátipos foi observada alguma variação no colorido, em vez da faixa amarela e ferrugínea, com máculas amarelas nos lados e nódoas dorsais amarelas pequenas, ou máculas amarelas grandes laterais e uma estria muito fina ferrugíneo-enegrecida dorsal. Epanthidium flavoclypeatum sp. nov., pelas faixas amarelas largas dos três tergos basais, lembra E. aureocinctum, que difere pelas mandíbulas amarelas, máculas paroculares amarelas largas inferiormente e muito estreitas na parte dorsal (Fig. 7), nódoas ferrugíneas nos flancos do vértice e manchas amarelas na base do mesoscuto. Na chave de Urban 1995, $E$. flavoclyopeatum sp. nov. entra com A. chapadense sp. nov. e A. aureocinctum.

\section{Austrostelis amapaensis sp. nov.}

(Figs. 8 e 11)

Diagnose. Macho com mácula preta frontal e o restante da face amarelo-âmbar, sem estria preta subantenal, occipício e labro pretos; faixa amarela no tergo basal e amarelo-pálida do segundo até o sexto tergo; terceiro esterno com pêlos longos e arqueados dos lados e uma área central de pêlos mais curtos formando uma franja reta.

Holótipo macho. Comprimento aproximado 5,36; comprimento da asa anterior a partir do ápice do esclerito costal 4,39; largura da cabeça 1,95. Tegumento da cabeça amareloâmbar com uma grande mácula frontal preta com o contorno ventral em forma de "W", do ocelo mediano até os alvéolos antenais e destes às órbitas, incluindo os ocelos e parte do vértice, até a extremidade dorsal das órbitas; estria pós-ocelar amarelo-ferrugínea, unida com as faixas genais amareloferrugíneas, estas largas na parte dorsal e muito estreitas ventralmente sem contudo alcançar a articulação mandibular; labro, ponta das mandíbulas e occipício enegrecidos; antenas com o escapo amarelo-escuro e no restante amarelo-âmbar. Mesossoma predominantemente preto, com a ponta dos lobos pronotais, máculas laterais do mesoscuto largas em forma de "J" invertido e as axilas amarelo-âmbar; escutelo amarelo-claro menos no terço basal, enegrecido; mesepisternos e metepisternos com nódoa arredondada amarelo-escura, pequena nos mesepisternos e maior e mais dorsal nos metepisternos. Tégulas translúcidas, amarelo-âmbar; asas com as veias enegrecidas e tingidas de enegrecido junto à margem anterior. Pernas com as coxas em parte castanhas e em parte amarelo-pálidas; trocanteres castanhos, os fêmures anteriores e medianos amarelados com estria castanha e os posteriores com a área amarela reduzida; tíbias e tarsos anteriores e medianos amarelados, as tíbias posteriores em parte amareladas e em parte castanhas, os tarsos amarelados. Tergos pretos, o basal com faixa discal amarela muito estreita no meio e alargando para os lados, orlada de castanho tanto para a base como para o bordo; do segundo ao sexto tergo a faixa discal amarelo-pálida, no segundo a faixa estreita dorsalmente porém alargando nos lados do tergo, a faixa marginal translúcida castanha; do terceiro ao sexto tergo a faixa mais larga que nos anteriores e estreitando um pouco na parte ventral dos tergos; a faixa marginal translúcida castanho-acinzentada, porém no sexto enegrecida e muito estreita. Esternos castanhos com margem translúcida esbranquiçada nos basais, segundo esterno com máculas amarelas laterais.

Sexto tergo com elevação somente nos flancos, não carenada; sétimo tergo com o contorno em arco rebaixado e inflado no disco. Franja apical do terceiro esterno com os pêlos laterais longos arqueados para o meio e pêlos mais curtos formando uma franja de contorno reto medianamente, a franja reta ocupando mais da metade da margem do esterno.

Holótipo macho. "Brasil, Amapá, Rio Cajari / Martins 0 34'S 52 18'W / 17.IX.2001, G. A. R. Melo, / ninho AP4" (DZUP). Um parátipo macho com os mesmos dados do holótipo (DZUP).

\section{Austrostelis santaterezae sp nov.}

(Figs. 9 e 12)

Diagnose. Fêmea com o escutelo em grande parte amarelo; dois tergos basais pretos com nódoas amarelas látero-dorsais, do terceiro ao sexto tergo em grande parte amarelo-âmbar e do terceiro ao quinto tergo com faixa marginal translúcida amarelomélea.

Holótipo fêmea. Comprimento aproximado 6,86; comprimento da asa anterior a partir do ápice do esclerito costal 5,39; largura da cabeça 2,22. Tegumento preto predominando na cabeça e no mesossoma; clípeo com máculas laterais amarelas e uma área discal acastanhada entre as máculas; paroculares com mácula amarela até o vértice, na parte inferior chegando ao clípeo, estreitando gradativamente até a altura dos alvéolos; mácula amarela alongada no meio da face, da área supraclipeal até o ocelo mediano, com os contornos arredondados na supraclipeal e na metade ventral da fronte, aí com o dobro da largura, porém estreitando dorsalmente e com os contornos retos até o ocelo mediano; estria pós-ocelar amarela, contínua com as genais, estas largas porém não alcançando a articulação mandibular. Antenas castanhas, excetuando pequenas áreas castanho-esbranquiçadas na ponta do escapo, no pedicelo e flagelômero basal e uma estria ventral amarelo-palha no escapo. Mesoscuto com máculas laterais em "U" invertido, com os ramos laterais longos e os centrais ocupando $2 / 3$ do comprimento do mesoscuto; escutelo amarelo com as fóveas basais pretas; axilas amarelas. Tégulas amarelo-acastanhadas translúcidas, asas tingidas de castanhoamarelado na ponta, incluindo a célula marginal; mesepisternos com mácula amarela quase retangular junto à carena préepistermal; pernas castanho-enegrecidas, as coxas posteriores com nódoa amarela obscura; face posterior dos fêmures com 
nódoa amarela minúscula subapical; tíbias e tarsos anteriores e medianos castanho-pálidos, as tíbias anteriores e as medianas com a face anterior amarelada; tíbias e basitarsos posteriores enegrecidos. Dois tergos basais pretos dorsalmente, com faixas amarelas látero-dorsais, o segundo tergo com faixa marginal castanho-amarelada translúcida; demais tergos pretos na base, com larga faixa discal amarelo-âmbar e a margem translúcida amarelo-mélea, exceto no tergo distal com a margem preta e um pouco alargada no meio; no terceiro a margem translúcida mais larga que a faixa. Esternos basais castanhos, os demais com a base castanha, faixa discal amarelada estreita e a margem translúcida esbranquiçada, esterno distal castanho.

Holótipo fêmea. "Santa Tereza, ES / Brasil 26-30.XII.1967 / C. Elias col." (DZUP).

\section{Austrostelis silveirai sp. nov.}

(Figs. 10 e 13)

Diagnose. Macho com as máculas cefálicas amarelas e amarelo-ferrugíneas; tergo basal com faixas laterais amarelopálidas quase até o meio, o segundo preto com máculas laterais amarelas, terceiro ao quinto tergo com faixas laterais amarelas estreitas, interrompidas nos flancos.

Holótipo macho. Comprimento aproximado 6,57; comprimento da asa anterior a partir do ápice do esclerito costal 5,49; largura da cabeça 2,34. Tegumento preto predominando, incluindo as mandíbulas. Clípeo com faixa discal amarela, bissinuada ventralmente e com uma projeção dorsal em forma de ogiva; áreas paroculares amarelas inferiormente e amareloferrugíneas na parte dorsal, as máculas estreitando a meia distância dos alvéolos ao ocelo mediano e arredondadas na ponta; mácula amarelo-âmbar longa e larga no meio da face, da sutura epistomal até pouco acima das carenas interalveolares, estreitando a seguir e com a ponta dorsal arredondada; faixa pós-ocelar e as genas amarelo-ferrugíneos, as máculas genais estreitando muito ventralmente e terminando antes da articulação mandibular, a faixa pós-ocelar contornando dorsalmente os olhos porém separada das máculas paroculares por pequena área preta. Antenas amarelo-âmbar do escapo ao segundo flagelômero, demais artículos enegrecidos. Mesossoma com as seguintes áreas amarelo-âmbar: estria em "J" invertido nos lados do mesoscuto; grande parte das axilas e terço distal do escutelo. Tégulas translúcidas castanhas, asas tingidas de enegrecido; pernas com os dois artículos basais e parte dos fêmures pretos; nas anteriores a área preta curta na base da face posterior e ocupando quase toda a face ventral, tíbia e tarso amarelo-âmbar, os tarsômeros intermediários levemente acastanhados; nas pernas medianas o fêmur preto com mácula amarela alongada na face posterior, tíbias amarelo-âmbar com a face posterior acastanhada e os tarsos castanho-claros; as pernas posteriores com o fêmur, tíbia e tarso castanhos, ápice do fêmur e base da tíbia com mácula amarela. Tergo basal com faixas laterais amarelo-pálidas, mais largas nos flancos e muito estreitas no meio, o espaço entre as faixas pouco maior que o diâmetro do ocelo; segundo tergo preto dorsalmente, com máculas laterais amarelas; terceiro ao quinto com faixas laterais muito estreitas amarelas, no terceiro separadas por área preta maior que dois diâmetros de ocelo, as faixas laterais fragmentadas nos flancos, resultando pequenas máculas ventrais; no quarto tergo as máculas ventrais obsoletas; quinto só com faixas látero-dorsais; sexto e sétimo inteiramente pretos; esternos pretos.

Sexto tergo com elevação carenada somente nos flancos; sétimo tergo com o contorno em arco rebaixado e inflado no disco. Franja apical do terceiro esterno com os pêlos laterais mais longos e arqueados para o meio, encurtando gradativamente para o meio lembrando um recorte em arco.

Holótipo macho. "Abelhas da Zona / Metalúrgica MG / Pq Mangabeiras / 0759-1865" ; " Belo Horizonte MG / Brasil 27/11/1996 / J. Damasceno"; " Austrostelis ? / sp. 01 / F. A. Silveira det. 2000" (DZMG).

Etimologia. Nome em homenagem ao Dr. Fernando Amaral da Silveira, Departamento de Zoologia, UFMG.

Urban (1999) identificou um Austrostelis de Maracás, Bahia, como A. iheringi (Schrottky, 1910). O reestudo do espécime e a comparação com A. maranhensis Urban, 2005, levou a uma nova interpretação, como A. maranhensis, e a incluir sua ocorrência na chave para a identificação das espécies apresentada neste trabalho. O Prof. Fernando C. V. Zanella (comunicação pessoal e fotos de espécimes) coletou exemplares de $A$. maranhensis na Paraíba, no Pico do Jabre, município de Maturéia, próximo de Patos. Zanella \& Ferreira (2005), registraram macho e fêmea de A. catamarcensis que emergiram de ninho de Epanthidium tigrinum (Schtottky, 1905), em Patos, Paraíba.

\section{Chave para a identificação das espécies de Austrostelis} Machos

1. Segundo ao quarto tergo com quatro nódoas amarelas, as duas dorsais ovaladas. Sétimo tergo com tubérculos laterais rasos que resultam em uma aparência bilobada; terceiro esterno com franja apical densa, os pêlos pouco mais longos dos lados, não arqueados, todos inclinados para o meio. Argentina; Paraguai; Brasil, Paraíba, Minas Gerais, São Paulo, Rio Grande do Sul

A. catamarcensis (Schrottky, 1909).

Segundo ao quarto tergo não como acima; com faixa discal amarela ou amarelo-esbranquiçada completa ou faixas laterais finas. Sétimo tergo com protuberância discal, sem aparência bilobada; terceiro esterno com pêlos laterais longos arqueados para o meio ............. 2

2(1). Terceiro esterno com a franja apical longa nos flancos, os pêlos arqueados para o meio e franja mediana reta de pêlos nitidamente mais curtos ocupando aproximadamente a metade da margem do esterno; 
cabeça sem estria preta subantenal. Brasil, Amapá ... . A. amapaensis sp. nov.

Terceiro esterno com a franja apical encurtando para o meio porém sem franja reta no terço mediano e os pêlos laterais como acima; cabeça com estria preta subantenal

3

3(2). Mesepisternos amarelo-esbranquiçados com nódoa discal preta arredondada. Brasil, Maranhão, Bahia ... A. maranhensis Urban, 2005.

Mesepisternos pretos ou com nódoa ferrugínea ou amarela ... 4

4(3). Tergo basal preto com faixas laterais amarelas quase até o meio; segundo tergo preto, do terceiro ao sexto com faixas amarelas látero-dorsais muito estreitas. Brasil, Minas Gerais A. silveirai sp. nov.

Tergos com faixa discal completa amarela ou amareloesbranquiçada 5

5(4). Cabeça e mesossoma com desenhos amarelos; mesoscuto com máculas amarelas em "J" ou "U" invertido. Brasil, Minas Gerais, Rio de Janeiro, São Paulo, Paraná, Santa Catarina A. iheringi (Schrottky, 1910).

Cabeça e mesossoma com desenhos ferrugíneos e amarelos; mesoscuto com máculas ferrugíneas em "U” invertido. Argentina; Paraguai; Brasil, Mato Grosso, São Paulo A. zebrata (Schrottky, 1905).

Fêmeas

1. Tergo basal com faixas laterais amarelas largas; segundo ao quarto tergo com quatro nódoas amarelas, as duas dorsais ovaladas A. catamarcensis

Tergo basal com faixa amarela discal ou com nódoas látero-dorsais amarelas; segundo tergo preto ou com faixa amarela; demais tergos com faixa amarela completa ou fragmentada; sem nódoas amarelas dorsais ovaladas
2(1). Dois tergos basais pretos dorsalmente; do terceiro ao sexto tergo largamente amarelos com o bordo translúcido amarelado. Brasil, Espírito Santo

A. santaterezae $\mathbf{s p . ~ n o v . ~}$

Faixa amarela ou amarelo-pálida em todos os tergos .... 3

3 (2). Mesepisternos amarelo-esbranquiçados com nódoa pequena preta discal A. maranhensis

Mesepisternos pretos ou com mácula amarelo-ferrugínea ... 4

4(3). Cabeça com máculas ferrugíneas e amarelas; mesossoma com máculas ferrugíneas, o mesoscuto com duas máculas grandes em "U” invertido; pernas anteriores e medianas predominantemente ferrugíneas

A. zebrata.

Cabeça e mesossoma com máculas amarelas; máculas mesoscutais amarelas em "J" ou em "U” invertido; pernas predominantemente castanho-enegrecidas com máculas amarelas A. iheringi

Agradecimentos. Ao Prof. Dr. Albino Morimasa Sakakibara pela ilustração do trabalho e ao Prof. Dr. Fernando C. V. Zanella pelas sugestões apresentadas e por ter disponibilizado informações geográficas sobre A. maranhensis.

\section{REFERÊNCIAS}

Urban, D. 1995. Espécies novas de Epanthidium Moure (Hymenoptera, Megachilidae, Anthidiinae). Acta Biológica Paranaense 21: $1-$ 21. [“1992"].

Urban, D. 1999. Sobre o gênero Austrostelis Michener \& Griswold stat. n. (Hymenoptera, Megachilidae), com algumas modificações nomenclaturais. Revista brasileira de Zoologia 16: 181-187.

Urban, D. 2005. Novos Dianthidiini Neotropicais (Hymenoptera, Megachilidae). Acta Biológica Paranaense 32: 95-106. ["2003"].

Zanella, F. C. V. \& A. G. Ferreira, 2005. Registro de hospedeiro de Austrostelis Michener \& Griswold (Hymenoptera: Megachilidae) e de sua ocorrência na Caatinga. Neotropical Entomology 34: $857-858$.

Recebido em 27/09/2005; aceito em 27/01/2006 